DOI: $10.4274 /$ jarem.galenos.2019.2952

J Acad Res Med 2020;10(2):129-32

\title{
Supero-inferior Thyroidectomy Technique in Papillary Thyroid Carcinoma: Preliminary Results of Thirteen Cases with Intraoperative Nerve Monitoring
}

\author{
(1) Ahmet Serkan İlgün1, (1) Kadir Çağdaş Kazıkdaş2 \\ ${ }^{1}$ University of Health Sciences Turkey, Gaziosmanpaşa Training and Research Hospital, Clinic of General Surgery, İstanbul Turkey \\ ${ }^{2}$ Near East University Faculty of Medicine, Department of Otorhinolaryngology, Nicosia, Cyprus
}

Cite this article as: İlgün AS, Kazıkdaş KÇ. Supero-inferior Thyroidectomy Technique in Papillary Thyroid Carcinoma: Preliminary Results of Thirteen Cases with Intraoperative Nerve Monitoring. J Acad Res Med 2020;10(2):129-32

\begin{abstract}
Objective: This study aimed to investigate the novel use of a surgical technique using intraoperative nerve monitoring (IONM) technology in conjunction with supero-inferior thyroid dissection technique for selected cases of diagnosed papillary carcinoma. We also aimed to determine the minimal stimulation thresholds for the recurrent laryngeal nerve (RLN) before its insertion into the larynx through the cricothyroid membrane.

Methods: In this retrospective analysis, 13 consecutive patients (11 women, 2 men) aged $42-71$ years (median, 53 years) who underwent total thyroidectomy with a preoperative diagnosis of papillary thyroid carcinoma only were included. The supero-inferior dissection technique has been detailed within the manuscript. After completion of thyroidectomy, the minimum current enough to stimulate the RLN at the most distal point was measured and recorded.

Results: The mean minimum stimulation current was $0.26 \pm 0.07 \mathrm{~mA}$ and $0.25 \pm 0.07 \mathrm{~mA}$ on the left and right sides, respectively. No permanent or transient RLN paralysis was observed postoperatively.

Conclusion: The supero-inferior dissection technique may have advantages, such as identification of the RLN in a constant point even in nonrecurrent cases and low complication rates, but it still requires delicate and careful dissection based on our experience and should be combined with the IONM technique, if possible.

Keywords: Post-dissection current, recurrent laryngeal nerve, surgical technique
\end{abstract}

\section{INTRODUCTION}

Thyroidectomy is among the most commonly performed cervical surgery in countries that are endemic goiter regions. The main goal when treating thyroid diseases surgically is to present the patient with high quality of life by keeping the risk of complications to a minimum. The most common postoperative complications are hypoparathyroidism and recurrent laryngeal nerve (RLN) paralysis. The rates of RLN injury in total thyroidectomy cases can be as high as 10\%; however, published rates of RLN injury are thought to be underestimated because less satisfactory results are less commonly presented, and complication rates from low-volume clinics tend to be higher (1-3).

Monitoring the laryngeal nerves during thyroidectomy has been increasingly used over the past 20 years. Intraoperative nerve monitoring (IONM) aids in the differentiation of RLNs from other tissues during thyroidectomy, facilitates identification of

ORCID IDs of the authors: A.S.I. 0000-0002-4862-2891; K.Ç.K. 0000-0001-8251-2162. 
anatomical variations of RLN, and controls nerve integrity at the end of the surgery. The use of IONM has been advocated for highrisk thyroidectomy cases, such as reoperation, thyroidectomy for malignancy, thyrotoxicosis, and retrosternal goiter, where the rate of RLN palsy is considered to be higher (4-6).

Two different RLN identification methods are used during thyroidectomy. The classical approach involves locating the RLN in the tracheoesophageal groove and following it in the superior direction (infero-superior method), whereas the other approach identifies the nerve where it enters the larynx after superior pedicle ligation (supero-inferior), generally thought to be a highrisk method (7).

This retrospective cohort study elaborates a novel surgical technique using IONM in conjunction with supero-inferior dissection technique for selected cases of diagnosed papillary carcinoma. We also aimed to determine the minimal stimulation thresholds for RLN before its insertion into the larynx through the cricothyroid membrane. To the best of our knowledge, this is the first preliminary report of the supero-inferior total thyroidectomy technique performed in malignancies combined with IONM of RLN published in the English literature.

\section{METHODS}

In this retrospective analysis, 13 consecutive patients (11 women, 2 men) aged 42-71 years (median, 53 years) who underwent total thyroidectomy with a preoperative diagnosis of papillary thyroid carcinoma (PTC) only were selected. The local ethics committee approved the study, and written informed consents were gathered from the patients preoperatively. The surgeries were performed between January 2012 and March 2014 in a tertiary medical center, and IONM (Medtronic NIM-Response system, Medtronic Xomed, Jacksonville, FL, USA) was used in all patients to localize the RLN on both sides. Patients with previous neck or thyroid surgery were excluded. All patients underwent complete neck ultrasonography. Neither perithyroidal soft tissue invasion nor lymph node metastasis was detected on ultrasonographic evaluation. PTC was diagnosed using fine-needle aspiration biopsy preoperatively. Fiberoptic laryngoscopic examination of the vocal folds was performed pre- and postoperatively, and no vocal fold pathologies were present preoperatively. IONM was used in a standardized set-up in accordance with the published Randolph and Dralle (8) guidelines. Nerve monitoring was accomplished by placing an electromyography (EMG) endotracheal tube in contact with the vocal folds and a stimulating surface probe. Short-acting myorelaxants were used only during the induction anesthesia to avoid interference with EMG recordings throughout the surgery.

A 5-7 cm Kocher incision below the level of the cricoid cartilage was made to expose the thyroid gland. After the strap muscles were separated, the middle thyroid vein was ligated, and the upper pole of thyroid gland was extensively exposed by sharp and blunt dissection from the carotid sheath laterally and the trachea and cricothyroid muscle medially. The branches of superior thyroid artery were ligated separately to prevent injury to the external branch of the superior laryngeal nerve. After the ligation of upper pole vessels in close proximity to the gland, the upper pole was released, and it was possible to tract this part laterally with the help of Babcock forceps. A careful and bloodless dissection was continued under the level of the cricothyroid muscle, and the RLN was roughly identified at the point where the nerve entered the larynx with the aid of IONM by using a minimum of $1.5 \mathrm{~mA}$ stimulation current (Figure 1,2), and after clearly identifying the RLN, the dissection was extended downwards by tunneling and spreading the tissues overlying the RLN. After the completion of thyroidectomy, the minimum current enough to stimulate the RLN at the most distal point was measured and recorded.

\section{Statistical Analysis}

Statistical analyses were performed using the SPSS 22.0 statistical package (SPSS, Chicago, USA). Mean and median values were used for parametric and non-parametric variables, respectively, as results of descriptive statistics.

\section{RESULTS}

The median follow-up period was 5.5 months. Three patients had multicentric/multifocal disease. Tumor node metastasis staging system was used for postoperative clinical staging. One patient had T1a $(\leq 1 \mathrm{~cm})$, three patients had T1b, eight patients had T2, and one patient had T3a tumors. Neither lymph node metastasis nor perithyroidal soft tissue invasion was detected in any of the patients. All patients but one with micropapillary thyroid cancer underwent radioactive iodine therapy treatment. Patients were followed up in 4 month intervals with routine physical examination and thyroglobulin levels. The mean current was $0.26 \pm 0.07$ and $0.25 \pm 0.07 \mathrm{~mA}$ on the left and right sides, respectively (Table 1). No permanent or transient RLN paralysis was observed postoperative. One patient had hoarseness and dysphonia on the first postoperative day and during videolaryngoscopic examination, where generalized vocal fold edema and areas of minor hemorrhage on both sides with intact mucosa and normal vocal fold mobility were observed. This condition was thought to be a result of repeated stimulation of the RLNs in contact with the endolaryngeal tube during surgery, and it was managed with a single dose of intravenous prednisolone $(1 \mathrm{mg} / \mathrm{kg})$ and vocal rest. Two other patients developed hypocalcemia in the early postoperative period, but they became normocalcemic during their follow-up.

\section{DISCUSSION}

Intraoperative neuromonitoring is the gold standard for imaging and functional testing of the recurrent nerve during thyroid surgery, and this tool requires an experienced use of the EMG an intraoperative adaptation of the resection strategy (i.e., inferosuperior, supero-inferior approach, etc.), especially in cases of planned bilateral total thyroidectomy. In addition to increasing intraoperative safety and facilitating the surgical procedure, 
especially in the case of high-risk interventions, medical malpractice lawsuits are taking their effect in many countries in favor of routine use of IONM in thyroid surgery. The guidelines published by the American Academy of Otolaryngology-Head and Neck Surgery and the German Association of Endocrine Surgeons also advise the routine use of IONM in thyroid surgery to protect vocal cord function (7-9), whereas the American Head

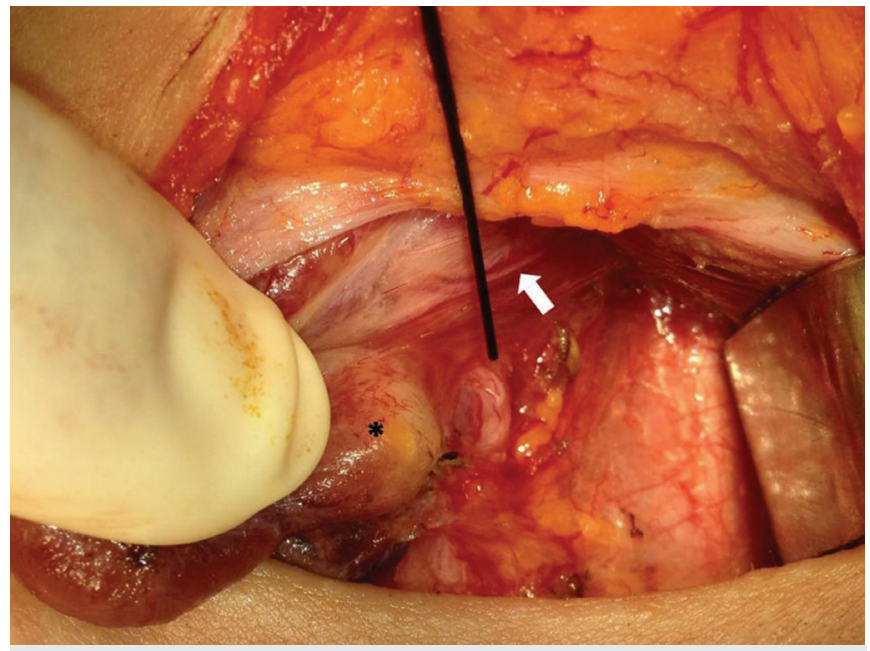

Figure 1. Intraoperative photo of left thyroid lobe (asterisk) after releasing the upper pole. The tip of the intraoperative nerve monitoring probe points at the left recurrent laryngeal nerve entering the larynx. The white arrow shows external branch of the superior laryngeal nerve

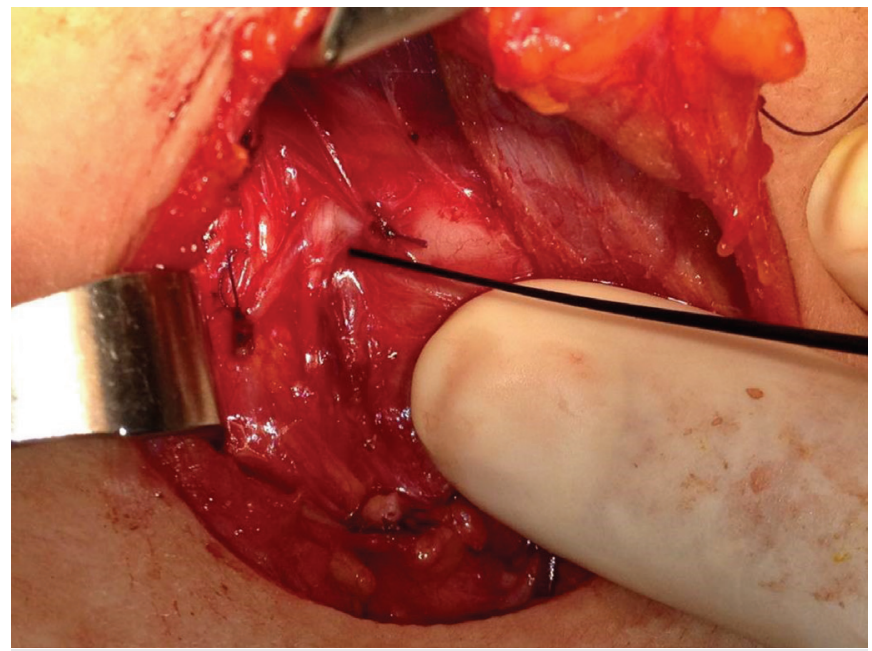

Figure 2. Photo documentation of the right recurrent laryngeal nerve (RLN) (tip of the probe) after completion of the surgery. The detection of minimal RLN stimulation threshold was performed at the most distal point through its infero-superior course

Table 1. Post-dissection minimum stimulation thresholds of the RLN

\begin{tabular}{|l|l|l|l|}
\hline & Right $(\boldsymbol{n}=13)$ & Left $(\mathbf{n}=13)$ & Range (minimum) \\
\hline Mean \pm SEM & $0.26 \pm 0.07 \mathrm{~mA}$ & $0.25 \pm 0.07 \mathrm{~mA}$ & $0.15 \pm 0.40 \mathrm{~mA}$ \\
\hline SEM: Standard error of the mean, RLN: Recurrent laryngeal nerve
\end{tabular}

and Neck Society endorses its utilization in thyroid cancer cases, particularly in patients with RLN palsy (1).

Although $1.5 \mathrm{~mA}$ stimulation current was used at the beginning of the surgery to roughly localize and map the neural structure overlaid by different types of tissues, proceeding with dissection, the minimal stimulation current needed for RLN to achieve a minimum EMG activity was $>100 \mu \mathrm{V}$ at its point of entry into the laryngeal region through the cricothyroid membrane. This point is presumed to be the most stable and reliable landmark in the RLN course, especially in non-recurrent variations. The detection of minimal stimulation threshold at the closest point to the larynx was made possible by using a descending method, thus lowering the stimulating current by $0.5 \mathrm{~mA}$ gradually until the EMG response on the screen was not recognizable. The mean minimum current at the end of the surgery was $0.26 \pm 0.07$ and $0.25 \pm 0.07 \mathrm{~mA}$ on the left and right sides, respectively. Only few studies in the literature investigated the stimulation thresholds in vivo: Choby et al. (10) found that the mean postresection RLN minimum threshold level was 0.47 mA (range: 0.20-1.0 mA), although the point of measurement through the course of the nerve has not been mentioned in the article. Using the same NIMRESPONSE monitoring system, the RLNs were monitored after thyroidectomy and parathyroidectomy in another prospective study, and the mean post-dissection stimulation threshold at the distal extremities of the nerve was $0.36 \mathrm{~mA}$ (range: $0.10-0.80 \mathrm{~mA}$ ), and the authors claimed that this great variability of thresholds could be explained by the degree of nerve dissection or the differences of nerve exposure to the stimulation electrode from one case to another because the nerve covered by a small amount of surrounding tissue, such as adipose or connective tissue, would require more intense stimulation (11). However, we managed to gather the most precise stimulation thresholds as possible with the closest proximity to the inlet of the RLN to the laryngeal region by using the supero-inferior dissection technique.

Postoperative vocal fold edema and hemorrhage can cause hoarseness due to relative vocal cord immobility with normal stimulation signal, which occurred in one of the patients; but normal mobility will be regained after the edema subsides (1). This issue points out the importance of pre- and postoperative laryngoscopic examination of the vocal cord function to diminish medicolegal liability and to differentiate previous vocal fold pathologies, such as vocal polyps or even pre-existing vocal cord paralysis (12).

In certain circumstances, such as reoperation, large goiters, cancers with extrathyroidal extension, and patients with very short neck, the RLN cannot be easily identified at the point where it crosses the inferior thyroid artery; thus, it could be wiser to look for it at its only constant anatomical point where it penetrates the laryngeal membrane at the top of the tracheoesophageal groove (13). This supero-inferior dissection technique was first described in 1988 by Guerrier (14). Although the supero-inferior dissection technique may have some advantages, such as identifying the RLN in a very constant point even in non-recurrent cases and low 
complication rates (7), it still requires more delicate and careful dissection based on our experience and should be combined with the IONM technique, if possible. Our sample size was relatively small due to the retrospective nature of the study, which included only cases with a preoperative diagnosis of PTC requiring total thyroidectomy, and the aim of this manuscript was to mainly describe the surgical technique and set the standard mean postdissection stimulation threshold of the RLN.

\section{Study Limitations}

The relatively small sample size and retrospective design are the main limitations of our study.

\section{CONCLUSION}

We aimed to investigate the use of IONM in conjunction with the supero-inferior thyroid dissection technique in elective bilateral total thyroidectomy for selected cases of preoperatively diagnosed PTC. Because inadvertent and repetitive use of high stimulus thresholds during such surgeries can fatigue the nerve cells and will potentially lead to postoperative paresis, the use of minimum currents for nerve stimulation is important. The superoinferior dissection technique has advantages, such as identifying the RLN in a very constant point even in non-recurrent cases and low complication rates, but it still requires delicate and meticulous dissection based on our experience and should combined with IONM, if possible.

Ethics Committee Approval: The local ethics committee approved the study.

Informed Consent: Written informed consents were gathered from the patients preoperatively.

Peer-review: Externally and internally peer-reviewed.

Author Contributions: Concept - A.S.I., K.C..K.; Design - A.S.I., K.Ç.K.; Supervision - A.S.I., K.Ç.K.; Resources - A.S.I., K.Ç.K.; Materials - A.S.I.; Data Collection and/or Processing - A.S.I.; Analysis and/ or Interpretation - A.S.I.; Literature Search - A.S.I., K.Ç.K.; Writing Manuscript - A.S.I.; Critical Review - A.S.I., K.Ç.K.

Conflict of Interest: The authors have no conflict of interest to declare.

Financial Disclosure: The authors declared that this study has received no financial support.

\section{REFERENCES}

1. Deniwar A, Kandil E, Randolph G. Electrophysiological neural monitoring of the laryngeal nerves in thyroid surgery: review of the current literature. Gland Surg 2015; 4: 368-75.

2. Liu X, Zhang D, Zhang G, Zhao L, Zhou L, Fu Y, et al. Laryngeal nerve morbidity in 1.273 central node dissections for thyroid cancer. Surg Oncol 2018; 27: 21-5.

3. Topal Y, Gedik ML, Karagoz I, Gonullu D, Arikan S, Tunalı V, et al. Total Tiroidektomi Yapılan Hastalarda, A. Thyroidea İnferior'un Trunkal Bağlanıp Bağlanmamasının ve N. Laryngeus İnferior'un Diseke Edilip Edilmemesinin Postoperatif Erken Dönem Kan Kalsiyumuna Etkisi. J Acad Res Med 2014; 2: 69-73.

4. Wong KP, Mak KL, Wong CKH, Lang BHH. Systematic review and metaanalysis on intra-operative neuro-monitoring in high-risk thyroidectomy. Int J Surg 2017; 38: 21-30.

5. Song $P$, Shemen L. Electrophysiologic laryngeal nerve monitoring in high-risk thyroid surgery. Ear Nose Throat J 2005; 84: 378-81.

6. Wu CW, Dionigi G, Barczynski M, Chiang FY, Dralle H, Schneider R, et al. International neuromonitoring study group guidelines 2018: Part II: Optimal recurrent laryngeal nerve management for invasive thyroid cancer-incorporation of surgical, laryngeal, and neural electrophysiologic data. Laryngoscope 2018; 128(Suppl 3): 18-27.

7. Veyseller B, Aksoy F, Yildirim YS, Karatas A, Ozturan O. Effect of recurrent laryngeal nerve identification technique in thyroidectomy on recurrent laryngeal nerve paralysis and hypoparathyroidism. Arch Otolaryngol Head Neck Surg 2011; 137: 897-900.

8. Randolph GW, Dralle H; International Intraoperative Monitoring Study Group, Abdullah H, Barczynski M, Bellantone R, et al. Electrophysiologic recurrent laryngeal nerve monitoring during thyroid and parathyroid surgery: international standards guideline statement. Laryngoscope 2011; 121(Suppl 1):1-16.

9. Musholt TJ, Clerici T, Dralle H, Frilling A, Goretzki PE, Hermann MM, et al. German Association of Endocrine Surgeons practice guidelines for the surgical treatment of benign thyroid disease. Langenbecks Arch Surg 2011; 396: 639-49

10. Choby G, Hollenbeak CS, Johnson S, Goldenberg D. Surface electrode recurrent laryngeal nerve monitoring during thyroid surgery: normative values. J Clin Neurophysiol 2010; 27: 34-7.

11. Julien N, Mosnier I, Bozorg Grayeli A, Nys P, Ferrary E, Sterkers O. Intraoperative laryngeal nerve monitoring during thyroidectomy and parathyroidectomy: A prospective study. Eur Ann Otorhinolaryngol Head Neck Dis 2012; 129: 69-76.

12. Postma DS, Becker MO, Roberts A, Gilleon S, Soto J. Thyroidectomy in a community hospital: findings of 100 consecutive cases. Ear Nose Throat J 2009; 88: 30.

13. Page C, Peltier J, Charlet L, Laude M, Strunski V. Superior approach to the inferior laryngeal nerve in thyroid surgery: anatomy, surgical technique and indications. Surg Radiol Anat 2006; 28: 631-6.

14. Guerrier Y. 3: la chirurgie du corps thyroïde. In: Traité de technique chirurgicale ORL et cervico-faciale Tome 4: cou et cavité buccale, 2ème éd. Editions Masson, Paris: 1998. p. 125-98. 